\title{
Perpetrator Religion and Perceiver's Political Ideology Affect Processing and Communication of Media Reports of Violence
}

\author{
Samia Habib ${ }^{1,2} \odot$, Levi Adelman ${ }^{1,3}$, Bernhard Leidner ${ }^{1}$, Shaheen Pasha ${ }^{4}$ \\ and Razvan Sibii ${ }^{1}$ \\ ${ }^{1}$ Department of Psychological and Brain Sciences, University of Massachusetts, Amherst, MA, USA \\ ${ }^{2}$ Department of Epidemiology, Boston University, MA, USA \\ ${ }^{3}$ Ercomer, Faculty of Social and Behavioral Sciences, Utrecht University, The Netherlands \\ ${ }^{4}$ Journalism Department, University of Massachusetts, Amherst, MA, USA
}

\begin{abstract}
People's interpretations of media reports about crimes may be biased by their motivations to construct and protect their worldviews and, relatedly, by criminals' group membership. Two large-scale experiments (Ns = 248 and 1,115) investigated how American adults interpret reports of crimes committed by either a Christian or Muslim, and how these interpretations depend on political ideology. Results show liberals attributing crimes more to religion for Christian rather than Muslim offenders, with the opposite effect for conservatives. Importantly, these biases also influenced how people communicated the news report to others. Additionally, evidence suggests that attitudes toward Islam and not toward Muslims may explain these effects. Implications for how political ideology affects interpretation and communication of media portrayals of Muslims are discussed.
\end{abstract}

Keywords: media, political ideology, motivated reasoning, religion

In recent years, there has been a series of high-profile masscasualty attacks across the Western world. In the wake of these tragedies, media outlets and everyday citizens try to understand why these attacks happened, often in the absence of sufficient information. For example, a shooting committed by two Muslims in San Bernardino, California, was quickly attributed to terrorism (Ifill, 2015), whereas a shooting by a Caucasian man in Las Vegas was quickly ruled to have not been an act of terrorism (Weaver \& Lartley, 2017). As with many real-world examples taken as anecdotal evidence, these cases differ on many levels. At the same time, they illustrate the possibility that members of the media, and people more broadly, may attribute criminal acts by Muslims to terrorism, while they attribute similar acts by Caucasians either to mental health or forgo an attribution altogether until more evidence can be gathered. Thus, people exposed to the same information can draw wildly diverging conclusions, with important downstream consequences for individual behavior and national policy.
The problem of biased attributions and processing is exacerbated as people tend to encounter and communicate news from within their social circles and selected niche media sources (Mitchell, Gottfried, Barthel, \& Shearer, 2016), raising the risk of media "echo-chambers" dividing segments of the population exposed to disparate sources of information (e.g., Barberá, Jost, Nagler, Tucker, \& Bonneau, 2015; Van Aelst et al., 2017). The consequences of such social divisions in processing media reports can have severe consequences not only for broader society, but also for the subjects of these media reports and members of their groups - especially when the subjects belong to minority groups. Therefore, it is important to study why these differences in perception and portrayal of similar actions by different social groups occur. Thus, this research seeks to better understand how people's biases, and especially people's political worldviews, shape the processing, interpretation, and communication of news stories about crimes committed by majority and minority perpetrators, respectively. Furthermore, this research investigates some 
competing arguments about the attitudes and beliefs that might help us understand why political worldviews might affect reactions to news reports of crimes committed by majority versus minority perpetrators.

\section{Bias in the Media}

Media are not just consumed passively, but they are engaged with, construed and interpreted actively. Many people are simultaneously consuming news themselves and reproducing news for others, and any biases they hold can affect this process. Indeed, research has found that when a crime is attributed to the race of the perpetrator, the outgroup minority members were seen as more dangerous than ingroup members who committed an identical crime (Chen, Purdie-Vaughns, Phelan, Yu, \& Yang, 2015). This attribution bias can have consequences for blame and punishment: a perpetrator labeled as a religious terrorist is more likely to be punished than a perpetrator labeled as mentally ill, because mental illness is associated with lack of control and intentionality (Hughes \& Trafimow, 2015), thus evoking more sympathy toward the perpetrator (Noor, Kteily, Siem, \& Mazziotta, 2019). Research has further shown that people consider whiter faces to be more likely to have committed an act of terrorism due to mental health rather than ideological reasons, and therefore assign them less guilt (Kunst, Myhren, \& Onyeador, 2018). Thus, if people blame crimes by Caucasians on mental health, they may then determine that the crime was likely less intentional because of reduced control. In contrast, if people blame crimes by minority members on religion or culture, they may be more likely to see these crimes as intentional. Once people ascribe greater intentionality to crimes by minority members, they may then assign harsher judgments and punishments to the minority actors (Ames \& Fiske, 2015).

Media biases can have other downstream consequences. If the media's negative portrayal of a certain group generates negative impressions of that group, whether explicitly or implicitly (e.g., Dovidio, Kawakami, \& Gaertner, 2002), these associations could increase prejudicial responses (Persson \& Musher-Eizenman, 2005). Therefore, biases in the production of news media do not only harm the factual content of the news, but they might also affect media consumers' perceptions and treatment of the social group of the perpetrator (see also Hoffman \& Wallach, 2007).

The unequal representation of minority versus majority group members in the media is especially an issue for Muslims. American media reports about Muslims are often very negative because Americans relate Islam with the 9/11 attacks committed by Islamic extremists (Persson \& Musher-Eizenman, 2005). Furthermore, news specifically related to terrorism can increase death-related thoughts, which in turn can increase prejudice (Das, Bushman, Bezemer, Kerkhof, \& Vermeulen, 2009). Therefore, an increased emphasis on Islam and terrorism in news reports can increase prejudice toward Muslims, whereas a reduced emphasis can decrease prejudice toward Muslims (Persson \& Musher-Eizenman, 2005). The present research will investigate how motivated reasoning grounded in political ideology produces such biased perception and reproduction of the news. Specifically, we aimed to test how liberals and conservatives, respectively, interpret crimes committed by minority Muslim and majority non-Muslim actors, and subsequently communicate these crimes to others.

\section{Political Ideology as Motivated Reasoning}

One potential source of bias in how people process and communicate news is their motivated reasoning: their unconscious motivations that affect their reasoning, attitudes, and behavior (e.g., Kunda \& Sinclair, 1999). People are generally motivated to only focus on evidence that supports their point and disregard much else (Epley \& Gilovich, 2016). Importantly, motivated reasoning can lead to biases and stereotypes toward people and events (Kunda, 1990). Thus, we hypothesized that, based on their worldview and ideological belief system, people would exhibit biased interpretation and attribution styles when processing as well as communicating crimes committed by minority Muslim or majority non-Muslim actors.

One prominent ideology that affects how people view the world is their political ideology (Kiley, 2017). Specifically, people's political worldviews may lead them to process information in the world around them in a way that matches their worldview (Jost, Glaser, Kruglanski, \& Sulloway, 2003). Thus, people's liberal or conservative ideologies shape their goals and beliefs, which in turn affect their unconscious motivations. Indeed, some research characterizes conservatives as high inconscientiousness and rigidity, desiring orderliness, and liberals as more open to new experiences, desiring novelty and diversity (Carney, Jost, Gosling, \& Potter, 2008). These differences in beliefs and values can lead conservatives and liberals to respond differently in the face of threat, fear, or uncertainty, with conservatives becoming more resistant to change and endorsing inequality (Jost et al., 2003), and liberals becoming more motivated by values of openness and diversity to support equality and social change (Carney et al., 2008).

Importantly, however, both conservatives and liberals exhibit biases in motivated reasoning (Kahan, 2013; Kahan, Jenkins-Smith, \& Braman, 2011). A recent meta-analysis found that liberals and conservatives show equal amounts of partisan bias (Ditto et al., 2017; see also Crawford, Kay, \& Duke, 2015). Indeed, recent research suggests that people adapt attributions of terrorism or mental health to 
criminal actions as a function of their political attitudes (Noor et al., 2019). Across multiple studies, Noor and colleagues (2019) found that people on both sides of the political spectrum interpreted the motivations of criminal actions in ways that protected their desired worldview and group image. Thus, initial findings suggest that political ideology may affect how a person interprets and portrays a crime depending on the race or religion of the perpetrator.

However, the past research leaves a few questions unanswered. First, it is not yet clear whether this bias is mainly or exclusively driven by conservatism (e.g., Jost et al., 2003), or also/equally by liberalism (e.g., Ditto et al., 2017). One perspective is that political conservatism, as an ideology that encompasses intergroup biases which promote ingroup superiority and ingroup dominance, might be expected to lead to situations in which liberals treat members of all groups identically while conservatives demonize and penalize outgroups (Hodson \& Busseri, 2012; Jost et al., 2003; Luguri, Napier, \& Dovidio, 2012). Alternatively, it may be that both liberals and conservatives are equally motivated to interpret world events in ways that protect their perspective on how the world should work. For liberals who desire and defend diversity (Carney et al., 2008), they may be especially motivated to support minority groups and try to focus on good actions and ignore or deny negative ones by those groups (Adelman, Yogeeswaran, \& Lickel, 2019) while being relatively more intolerant toward majority group members (Brandt, Reyna, Chambers, Crawford, \& Wetherell, 2014).

Second, while the importance of political ideology seems clear, it is less clear why political ideology would affect judgments about members of majority and minority groups. One perspective is that since political ideology reflects a wide-ranging worldview which includes attitudes toward other groups, liberals might judge a Muslim perpetrator equally or more positively than a Christian perpetrator because they hold more positive attitudes toward Muslims than Christians (Brandt et al., 2014). By contrast, conservatives who hold relatively more negative attitudes toward Muslims than non-Muslims, would judge Muslim perpetrators more negatively than Christian perpetrators. An alternative perspective is that the way people judge Muslim and non-Muslim perpetrators may not be due to attitudes toward the group, but might instead reflect beliefs they have about the content of the religion that might make them more or less likely to interpret that religion as being the source of violent behaviors. This approach reflects research suggesting that stereotypes, which are often perceived as a negative bias, may instead reflect relatively accurate judgments about groups (Jussim, Crawford, \& Rubinstein, 2015) or principled observations about other groups (e.g., Sniderman, Tetlock, Glaser, Green, \& Hout, 1989). Indeed, people on both sides of the political aisle can argue that their interpretation is the most probable interpretation, and that it is not influenced by bias. Therefore, to better understand the source and nature of biases grounded in political ideology, two large-scale experiments investigated how people with varying political ideologies interpret crimes committed by members of a stigmatized minority group (Muslims) compared to crimes committed by members of a less or non-stigmatized group (Christians).

\section{Hypotheses}

Our aim was to understand if political ideologies affect how people perceive and report a crime depending on the religion of the perpetrator. Specifically, we hypothesized that people's political ideology and the offender's group membership jointly affect how much people attribute the crime to religion (as a group-level factor) or mental health (as an individual factor). Furthermore, we proposed that political ideologies would bias people on both the right and the left to interpret information in ways consistent with their worldviews. We thus expected relatively conservative people to be more likely to conclude that a crime committed by a Muslim (rather than Christian) perpetrator was primarily due to religion, while concluding that a crime committed by a Christian (rather than Muslim) perpetrator was primarily due to mental health problems. Conversely, we expected relatively liberal people to attribute a crime committed by a Christian (rather than Muslim) perpetrator was primarily due to religion, while attributing a crime committed by a Muslim (rather than Christian) perpetrator was primarily due to mental health problems. We also tested two competing explanations for why political ideology might affect judgments of Muslim versus Christian perpetrators. Specifically, we included measures of attitudes toward Muslims and attitudes toward Islam to test whether the effects are explained by negative attitudes toward a group of people, or negative attitudes toward a religion or ideology.

For both experiments, we report how we determined our sample size, all data exclusions (if any), all manipulations, and all measures in the study (Simmons, Nelson, \& Simonsohn, 2011). Due to space limitations, reports of some outcome measures can be found in the supplemental file. All data were collected prior to any data analysis.

\section{Experiment 1}

Experiment 1 tested our hypotheses in a convenience sample of psychology and journalism undergraduate students, using a between-subject design in which participants were randomly assigned to read about either a Christian or a Muslim perpetrator. 


\section{Method}

\section{Participants}

We recruited 248 participants from a large university to participate in this study. Of these participants, 48 were recruited specifically from journalism courses and an additional 200 were recruited from the general student population accessible via the psychology subject pool. Participants completed the 30-minute study for course credit or $\$ 10$. The survey was completed on paper in classrooms or in research labs. All participants were included in the analyses. Participants were mostly female $(76.0 \%$ female; $23.6 \%$ male; $0.4 \%$ non-identified), between 17 and 31 years old $(M=20.24, S D=1.79)$, and on average significantly left of the political center $(1=$ very liberal, $6=$ very conservative; $M=2.63, S D=1.05, t(240)=38.77, p<.001)]$.

\section{Measures}

\section{Experimental Manipulation}

Participants were randomly assigned to read a crime scenario with either a Muslim (Ahmed Yusuf) or Christian (Matthew Clark) perpetrator, which described a shooting at a university that injured 13 students, and noted the religion, mental health, social life, and childhood of the perpetrator. The scenario was identical across conditions except for the name and religious identifiers of the offender (see Electronic Supplementary Material, ESM 1).

\section{Interpretation of the Crime Scenario}

We included a number of measures to understand how participants interpreted the crime they read about.

To compare different attributions for the crime, we measured to what extent participants attributed the crime to the offender's religion, mental health, social life, and difficult childhood on a scale from 1 (= completely disagree) to 6 (= completely agree). Four items $(\alpha=.80)$ also measured, on a scale from 1 (=none) to 6 (=very much), to what extent participants believed the offender was feeling guilt, shame, pain, and pleasure (reverse-scored). To measure intentionality, four items $(\alpha=.87)$ measured to what extent participants believed the offender had intended the crime (e.g., "How much do you think the incident was intentional?"), on a scale from 1 (= none) to 6 (= very much). Finally, five items measured, on a scale from 1 (= extremely unlikely) to 6 (= extremely likely), how likely participants believed it to be that the offender had been targeting a specific group as a "hate crime" (e.g., "members of a specific race or religion"). However, the items did not form a reliable scale and were not analyzed.

\section{News Production Based on the Crime Report}

We next asked participants a series of questions designed to understand how they would communicate the news to others.
After reading the scenario, participants wrote a minimum 200-word news report about the incident, which we analyzed based on the use of keywords related to religion and mental health. We also assessed which of the four details about the perpetrator (i.e., religion, mental health, social life, and childhood) participants would prioritize in their reports using a rank-order measure. On a scale from $1(=$ none $)$ to $6(=a l o t)$, participants rated four items measuring how much time they would spend investigating the four different aspects of the offender's life mentioned in the report (religion, mental health, social life, and difficult childhood). Lastly, participants were asked to rate, on a scale from 1 (= extremely unlikely) to 6 (= extremely likely), how likely they would be to use each of seven headlines for the article they had written (e.g., "Student critically injures 3 people during a shooting"; "3 people injured during a possible [Christian/Muslim] terrorist attack").

\section{Process Variables}

We measured political ideology as a moderator using four statements $(\alpha=.90)$ measured, on a continuous scale from 1 (= extremely liberal) to 6 (= extremely conservative), participants' political ideology (e.g., "Regarding economic issues [e.g., taxation, public spending], I am..."). We also included potential mediators using statements to measure attitudes toward Muslims, Islam, Arabs, and the portrayal of Muslims in the media (e.g., "Arabs are a threat for America"; "I would like to be friends with Muslims"; "Islam is radical and intolerant"; "People believe that the negative media portrayal of Arabs is justified"). These were all measured on a scale from 1 (= completely disagree) to 6 (= completely agree).

\section{Results}

We analyzed the main and interaction effects of the offender's religious group membership and participants' political ideology on the dependent variables using mixed analysis and moderated regression analysis. Due to space constraints, we only report main effects that reached significance; additionally, we only report the results for a subset of the dependent variables. Details and results from the other variables can be found in the supplemental file.

\section{Interpretations of the Crime Scenarios Attributions for the Crime}

To examine whether participants attributed the crime to the offender's religion or mental health, we conducted a mixed analysis with offender religion and political ideology as between-subject factors, and participants' attributions of 
the crime to either religion or mental health as a two-level within-subject factor. ${ }^{1}$ The three-way interaction was significant, $F(1,236)=15.14, p<.001, \eta_{\mathrm{p}}{ }^{2}=.060$, indicating that the interaction between perpetrator religion and political ideology differed for attributions of the crime to mental health versus religion. Therefore, we tested the two-way interaction effects of perpetrator religion and political ideology on attributions of the crime to religion and on attributions of the crime to mental health separately. The interaction between perpetrator religion and political ideology was significant for attributions to religion, $F(1,236)=$ 12.00, $p<.001, \eta_{\mathrm{p}}{ }^{2}=.048$, such that increasing liberal (and decreasing conservative) attitudes predicted marginally greater attributions of the crime to religion when the offender had been described as Christian, $B=-.14, S E=$ $.08, t(236)=-1.90, p=.058$, but significantly weaker attributions of the crime to religion when the offender had been described as Muslim, $B=.23, S E=.08, t(236)=2.98, p=$ .003 . As Figure 1 shows, this resulted in liberals $(-1 S D$ on political ideology) attributing the crime to a lesser extent to religion when the offender had been described as Mus$\lim (M=2.01)$ rather than Christian $(M=2.83), t(236)=$ $5.31, p<.001, d=0.69$. In contrast, there was no significant difference among conservatives $\left(+1 S D ; M_{\text {Muslim }}=2.48\right.$, $\left.M_{\text {Christian }}=2.54\right), t(236)=.410, p=.684, d=0.05$. A significant main effect of perpetrator religion also showed that participants overall attributed the crime more to religion when the perpetrator was Christian $(M=2.68, S D=$ $0.80)$ rather than Muslim $(M=2.24, S D=0.90), F(1$, 236) $=16.39, p<.001, \eta_{\mathrm{p}}^{2}=.065$.

The interaction between perpetrator religion and political ideology was also significant for attributions to mental health, $F(1,236)=4.13, p=.043, \eta_{\mathrm{p}}{ }^{2}=.017$. Here, however, increasing conservative attitudes predicted marginally greater attributions of the crime to mental health when the offender had been described as Christian, $B=.17, S E$ $=.09, t(236)=1.91, p=.056$, but did not significantly predict attributions of the crime to mental health when the offender had been described as Muslim, $B=-.09, S E=$ .09, $t(236)=-.980, p=.329$. Thus, liberals attributed the crime significantly more to mental health when the offender had been described as Muslim $(M=3.95)$ rather than Christian $(M=3.59), t(236)=-2.07, p=.039, d=-0.27$, whereas conservatives' attributions again did not significantly depend on offender religion $\left(M_{\text {Muslim }}=3.78, M_{\text {Chris- }}\right.$ tian $=3.92), t(236)=.810, p=.417, d=0.11$. The results for offender remorse and offender intentionality were similar and significant and can be found in ESM 1.

Panel A: Exp. 1 Attributions to religion

3.5

3

2.5

2

1.5



Panel B: Exp. 1 Attributions to mental health

4.5

3.5

2.5

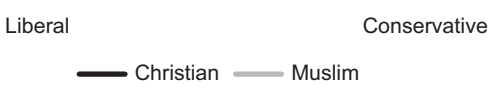

Figure 1. The effects of political orientation when the offender was either Christian (black lines) or Muslim (gray lines) on attributions for the crime to religion (Panel A) and mental health (Panel B) in Experiment 1.

\section{Measures of News Production Written Reports}

We also evaluated participants' written reports about the crime scenario to test how the offender's religious group membership and participants' political ideology would affect how people communicate crimes to others. Specifically, based on the content of the scenario participants had been given, we created a list of words related to religion and the situational context participants were describing (e.g., Islam-, Christ-, Quran, Bible, mosque, church) and mental health (e.g., mental, health, depress, psych) and calculated the overall total of words in each category that were used, while controlling for the overall number of words used (see ESM 1 for the complete list of words). For this analysis, the data of three participants were excluded because they wrote about unrelated events.

For words associated with religion, we found a marginally significant interaction, $F(1,226)=3.74, p=.054$, $\eta_{\mathrm{p}}^{2}=.016$, indicating that the effect of political ideology on the use of words associated with religion (i.e., the slopes

\footnotetext{
'For ease of presentation, when reporting analyses of mixed models where the four aspects of the offender's life are included (i.e., religion, mental health, social life, and childhood), we report the results for the two most theoretically interesting aspects, namely religion and mental health.
} 
of political ideology) differed when the perpetrator was Christian compared to Muslim, $B=.55, S E=.28, t(226)=$ $1.93, p=.054$. Simple sloped analysis revealed that while neither simple slope differed significantly from zero, the two slopes significantly differed from each other. When the perpetrator was Christian, increasing conservatism decreased the use of religious words, $B=-.22, S E=.20$, $t(226)=-1.14, p=.254$, whereas when the perpetrator was Muslim, increasing conservatism increased the use of words associated with religion, $B=.32, S E=.20, t(226)=$ $1.57, p=.117$; see Figure 2 . The simple effects at high $(+1$ $S D)$ and low $(-1 S D)$ were not significant, $t s<1.49, p\rangle$ .138. For words associated with mental health, the twoway interaction was not significant, $F(1,226)=1.52, p=$ $.219, \eta_{\mathrm{p}}^{2}=.007$.

Sample essays (see ESM 1) illustrate how participants distinguished between perpetrators based on their religion. For example, a liberal participant in the Christian condition reported at the beginning of their essay that "[Matthew Clark] had been frequenting online Christian chat rooms and looking for local religious groups", whereas a liberal participant in the Muslim condition did not mention religion at all, but rather reported that "[Ahmed] Yusuf did not have any friends on campus... he was a victim of cyber bullying in high school, and that he became even more reserved after the incident, refusing to leave his room for weeks at a time." Meanwhile, a conservative participant in the Christian condition avoided religion and rather stated that "Clark's behavior prior to the attack indicates that he was a troubled young man. His therapist, whom he had been seeing for a month prior to the shooting indicated Clark showed symptoms of being clinically depressed." A similarly conservative participant in the Muslim condition mentioned religion first, stating that "Officers found religious verses and symbols on his side of the room... and found that Yusuf had recently spent a lot of time looking for Muslim chat groups online and local religious groups." Of course, the samples cannot be taken as full representations of how liberals and conservatives reported on these crimes, though they do illustrate the decisions participants made in communicating these crimes to others.

\section{Ranked Prioritization of Offender's Experiences}

We also examined which aspect of the offender's life participants prioritized reporting about, using a mixed analysis with offender religion and political ideology as betweensubject factors, and the aspect of the offender's life as a two-level within-subject factor (religion vs. mental health). The three-way interaction, $F(1,234)=8.35, p=.004, \eta_{\mathrm{p}}{ }^{2}$ $=.034$, indicated that the interaction between offender religion and political ideology differed depending on which aspect participants were ranking. To disentangle this three-way interaction, we tested for the two-way interaction
Panel A: Exp. 1 words related to religion

4.5

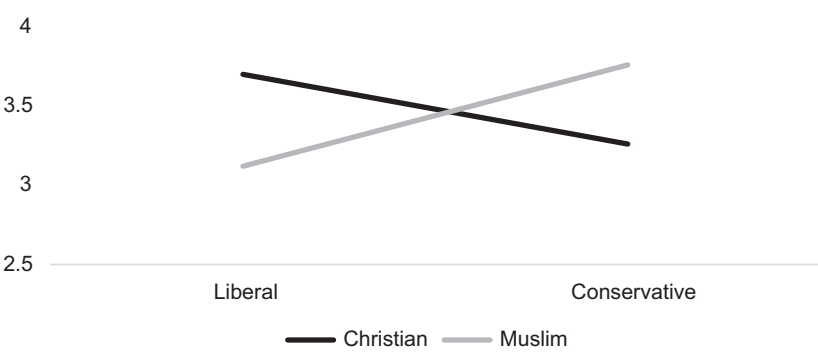

Panel B: Exp. 1 words related to mental health 3.5

3

2.5

2

1.5

Liberal

Conservative

Christian Muslim

Figure 2. The effect of political orientation when the offender was either Christian (black lines) or Muslim (gray lines) on use of words associated with religion (Panel A) and mental health (Panel B) in Experiment 1 .

between political ideology and offender religion on each aspect separately. Importantly, note that as this is a ranking variable (1-4), lower numbers indicate a higher ranking and thus greater importance for a given concept.

For religion, the main effect of perpetrator religion was significant, $F(1,234)=17.13, p<.001, \eta_{\mathrm{p}}{ }^{2}=.068$, such that participants prioritized religion less when the perpetrator was Muslim $(M=2.94, S D=1.25)$ rather than Christian $(M=2.27, S D=1.30)$. This effect was moderated by a significant interaction, $F(1,234)=10.92, p<.001, \eta_{\mathrm{p}}{ }^{2}=.045$, such that increasing liberal (and decreasing conservative) attitudes predicted increased prioritization of religion when the offender had been described as Christian, $B=.31$, $S E=$ $.11, t(234)=2.73, p=.007$, but marginally decreasing prioritization of religion when the offender had been described as Muslim, $B=-.23, S E=.12, t(234)=-1.96, p=.051$. From another perspective, liberals prioritized reporting on religion when the offender had been described as Christian $(M=1.95)$ rather than Muslim $(M=3.16), t(234)=-5.27$, $p<.001, d=-0.69$, while conservatives did not differ significantly $\left(M_{\text {Muslim }}=2.70, M_{\text {Christian }}=2.57\right), t(234)=-.580$, $p=.562, d=-0.08$.

For mental health, the main effect of perpetrator religion was again significant, $F(1,234)=8.83, p=.003, \eta_{\mathrm{p}}^{2}=.036$, 
such that participants prioritized mental health more when the perpetrator was Muslim $(M=2.68, S D=1.11)$ rather than Christian $(M=3.08, S D=1.01)$. This effect was moderated by a marginal interaction, $F(1,234)=3.79, p=.053, \eta_{\mathrm{p}}{ }^{2}=$ .016 , with increasing liberal (and decreasing conservative) attitudes predicting lower prioritization of mental health when the offender had been described as Christian, $B=$ $-.20, S E=.10, t(234)=-2.07, p=.039$, but having no effect when the offender had been described as Muslim, $B=.07$, $S E=.10, t(234)=.710, p=.478$. A simple effects perspective revealed that liberals prioritized reports about the offenders' mental health more when the offender was Muslim $(M=$ 2.61) rather than Christian $(M=3.27), t(234)=3.48, p<$ $.001, d=0.45$, while conservatives did not differ $\left(M_{\text {Muslim }}\right.$ $\left.=2.75, M_{\text {Christian }}=2.89\right), t(234)=.720, p=.473, d=0.09$.

\section{Examining the Underlying Process}

To better understand why political ideology had this effect on processing and disseminating news about offenders who differ on their religion, we investigated two competing arguments. First, that political ideology comprises negative intergroup attitudes (Jost et al., 2003) and therefore those who like and dislike the target group adapt their responses to better fit their worldviews. Second, that people from different political ideologies may differ in their moral values (Graham, Haidt, \& Nosek, 2009) and therefore have principled reasons to reject a different religion or to find it more likely to be threatening (Sniderman et al., 1989). Therefore, we conducted mediation analyses where we pitted measures of these two competing perspectives against each other: attitudes toward Muslims and attitudes about Islam.

Process analysis (Hayes, 2013) revealed an indirect effect of political ideology on attitudes toward Islam, $B=-.47, S E$ $=.05, t(234)=-8.64, p<.001,95 \%$ CI $[-.575,-.362]$, which in turn, moderated by religion of the perpetrator, predicted attribution of the crime to religion, $B=-.37, S E=.14$, $t(234)=-2.67, p=.008,95 \%$ CI $[-.643,-.096]$. This mediation path was significant when the perpetrator was Muslim, $B=.19$, Boot $S E=.06$, 95\% CI [.083, .305], rather than Christian, $B=.01$, Boot $S E=.05,95 \%$ CI [-.074, .113], and the direct effect of political ideology was no longer significant, indicating that participant attitudes toward Islam partially explained why political ideology interacted with perpetrator religion to determine attributions to religion. Neither of the other two mediation models was significant for either attitudes toward Muslims or attitudes toward Islam.

Thus, a mediation analysis suggested a role for attitudes toward Islam but not attitudes toward Muslims, which might suggest a principled rejection of the religion which is based in an understanding of Islam rather than a prejudice toward Muslims driving this effect. To test this explanation of the source of attitudes toward Islam, we predicted attitudes toward Islam through knowledge of Islam and political ideology and found no significant effect, $F(1,234)$ $=.12, p=.733$, suggesting that a basic knowledge of Islam did not seem to play any role in people's attitudes toward Islam, both among conservatives and liberals. The mediation analyses above included knowledge of Islam as a covariate, with no effect on the overall mediation.

\section{Discussion}

Experiment 1 found consistent evidence for motivated reasoning on the basis of political ideology. Supporting the hypothesis that motivated reasoning bias can also be driven by liberalism (rather than exclusively by conservatism), Experiment 1 found that liberals consistently emphasized the role of religion in crimes committed by a Christian (rather than Muslim) while simultaneously emphasizing the role of mental health in crimes committed by a Muslim (rather than Christian) in interpreting and disseminating a news report. Conservatives, on the other hand, did not differ based on the offender's religious group membership. Importantly, these results emerged not only in how participants processed information, but also in how they communicated it to others. These results partially support the hypothesis that people interpret as well as communicate information in ways that are consistent with politically preferred conclusions about the specific incidents in question. Yet, this motivated reasoning and communication bias was only found for liberals, but not conservatives. It was not clear, however, whether the null findings among conservatives indicate that conservatives do not have such bias, or whether, due to the sampling methodology of Experiment 1 , the left-leaning sample may not have included participants who were sufficiently conservative to detect such bias. Experiment 1 also found preliminary evidence that attitudes toward Islam, and not attitudes toward Muslims, may explain some of the effect of political ideology specifically on attribution of a crime to religion.

\section{Experiment 2}

Experiment 2 sought to replicate Experiment 1 in a large sample of American adults recruited online through Amazon Mechanical Turk. As Experiment 1 drew from a relatively young and liberal set of participants (college students in the Northeastern United States), we aimed to test whether similar evidence of motivated reasoning based on political ideology would emerge for a larger sample that was more representative in both age and political ideology. 


\section{Method}

\section{Participants}

We recruited 1,115 participants online through Amazon Mechanical Turk. Participants were mostly female (female: $58.2 \%$, male: $40.9 \%$, non-identified: $0.6 \%$, other: $0.4 \%$, between 18 and 79 years old $(M=36.89, S D=12.69)$, and their political ideology was close to the scale midpoint $(\alpha=.94 ; M=3.27, S D=1.40,1=$ very liberal, $6=$ very conservative). The study took about 30 min to complete, and participants were compensated with 50 cents for their participation.

\section{Measures}

The measures and procedure were identical to those in Experiment 1. However, we added questions about the 2012 and 2016 presidential elections.

\section{Results}

\section{Interpretations of the Crime Scenarios Attributions for the Crime}

Consistent with Experiment 1, a mixed analysis with offender religion and political ideology as between-subject factors and participants' attributions of the crime to either religion or mental health as a two-level within-subject factor revealed a significant three-way interaction, $F(1,1,066)=$ $39.15, p<.001, \eta_{\mathrm{p}}{ }^{2}=.035$, indicating that the interaction between offender religion and participant political ideology differed based on the type of attribution. When attributions were made based on religion, a significant main effect of perpetrator religion revealed that people attributed the crime more to religion when it was committed by a Muslim $(M=2.98, S D=1.22)$ rather than a Christian $(M=2.69, S D$ $=1.13), F(1,1,066)=19.64, p<.001, \eta_{\mathrm{p}}^{2}=.018$. A main effect of political ideology also revealed that the more conservative participants were, the more they attributed the crime to religion, $B=.25, S E=.03, t(1,066)=7.11, p<$ .001. These effects were moderated by a significant twoway interaction, $F(1,1,066)=46.44, p<.001, \eta_{\mathrm{p}}{ }^{2}=$ .040 , where increasing liberal (and decreasing conservative) attitudes predicted significantly weaker attributions of the crime to religion when the offender had been described as Muslim, $B=.48, S E=.05, t(1,066)=9.65$, $p<.001$, but political ideology did not have a significant effect on attributions of the crime to religion when the offender had been described as Christian, $B=.01, S E=$ $.05, t(1,066)=.220, p=.829$. A simple effects analysis revealed that liberals were marginally more likely to attribute the crime to religion when the offender was Christian $(M=2.68)$ rather than Muslim $(M=2.52), t(1,066)=1.69$, $p=.091, d=0.10$, while conservatives were significantly more likely to attribute the crime to religion when the
Panel A: Exp. 2 Attributions to religion

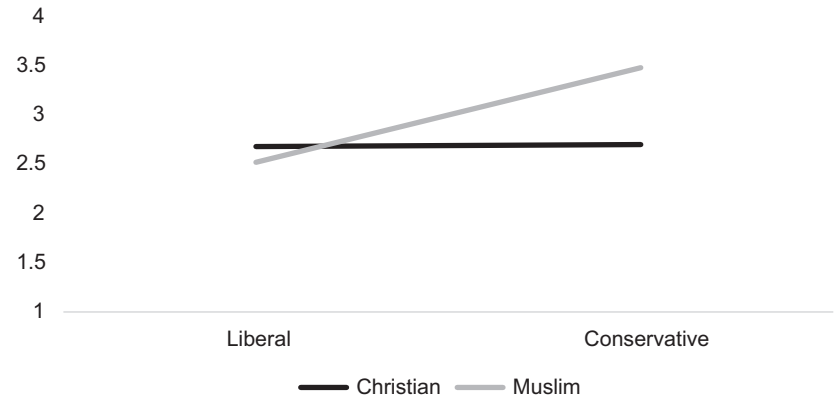

Panel B: Exp. 2 Attributions to mental health

4.5

4

3.5

Liberal

Conservative

Figure 3. The effects of political orientation when the offender was either Christian (black lines) or Muslim (gray lines) on attributions for the crime to religion (Panel A) and mental health (Panel B) in Experiment 2.

offender was Muslim $(M=3.48)$ rather than Christian ( $M$ $=2.70), t(1,066)=-7.95, p<.001, d=-0.49$. The twoway interaction on attribution to mental health was not significant, $F(1,1,066)=.85, p=.356, \eta_{\mathrm{p}}{ }^{2}=.001$. See Figure 3.

\section{Measures of News Production Written Reports}

As in Experiment 1, we evaluated participants' written reports about the crime scenario to see how the offender's religion and participants' political ideology would affect how much participants focused on religion and mental health when communicating the crime to others. Using the same set of words as in Experiment 1 to indicate focus on religion and mental health (see ESM 1), we analyzed participants' written reports. One hundred and four participants were excluded from this analysis for irrelevant writings.

When looking at the use of words associated with religion, we found a main effect of offender religion, $F(1$, 971) $=6.27, p=.013, \eta_{\mathrm{p}}{ }^{2}=.006$, such that people used more words associated with religion when the offender was portrayed as Muslim $(M=2.85, S D=2.59)$ rather than Christian $(M=2.67, S D=2.66)$. This effect was moderated by a significant two-way interaction between perpetrator 
religion and participant political ideology, $F(1,971)=6.25$, $p=.013, \eta_{\mathrm{p}}{ }^{2}=.006$. Specifically, the effect of political ideology on the use of words associated with religion (i.e., the slopes of political ideology) differed when the perpetrator was Christian compared to Muslim, $B=.33, S E=.13$, $t(971)=2.50, p=.012$. When the perpetrator was Christian, increasing conservatism and decreasing liberalism were associated with a nonsignificant tendency to use less religious words, $B=-.13, S E=.09, t(971)=-1.47, p=.142$, whereas when the perpetrator was Muslim, increasing conservatism and decreasing liberalism led to more use of words associated with religion, $B=.19, S E=.09, t(971)=$ $2.05, p=.040$. A simple slopes analysis revealed that, in contrast to Experiment 1, conservatives used more words related to religion with a Muslim $(M=3.12)$ compared to a Christian offender $(M=2.47), t(971)=-3.43, p<.001$, $d=-0.22$, with no difference emerging among liberals $\left(M_{\text {Muslim }}=2.73 ; M_{\text {Christian }}=2.73\right), t(971)=.01, p=.994$, $d=0.00$ (see Figure 4, Panel A).

Similarly, with respect to mental health, the two-way interaction was significant, $F(1,971)=4.83, p=.028$, $\eta_{\mathrm{p}}{ }^{2}=.005$. Once again, the effect of political ideology on mental health words differed based on perpetrator religion, $B=-.20, S E=.09, t(971)=-2.20, p=.028$. While neither simple slopes significantly differed from zero, the interaction was driven by how they differed from each other. With a Christian perpetrator, increasing conservatism and decreasing liberalism were associated with a tendency to use more mental health words, $B=.08, S E=.06, t(971)=$ $1.30, p=.195$, whereas with a Muslim perpetrator, increasing conservatism and decreasing liberalism led to somewhat less use of mental health words, $B=-.12$, $S E=$ .06, $t(971)=-1.80, p=.072$ (see Figure 4, Panel B). The simple effects were nonsignificant.

Once again, reviews of sample essays (see ESM 1) illustrate how participants used or emphasized religious or mental health themes in their reports. A liberal participant wrote about a Christian perpetrator saying early on in the essay that "many religious items were found and... he had been spending a lot of time in Christian chat groups recently." A liberal participant writing about a Muslim, however, reported first that "witnesses report Yusuf had recently been seeing a counselor at the university who believes Yusuf was suffering from depression... At the time of the shooting, Yusuf was not taking any medication to combat his depression." Sample essays by conservatives illustrate a reverse approach. When writing about a Christian, a conservative participant reported that "Clark had engaged in many social activities but had recently withdrawn from almost all interaction. Speaking to the chaplain on campus, found that Clark had become more involved in religious activities. Clark had also recently sought counseling for depression, but had not been formally diagnosed. An

Panel A: Exp. 2 words related to religion

3.5

3

2.5

2

1.5

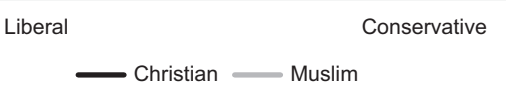

Panel B: Exp. 2 words related to mental health 4

3.5 3 2.5 2 1.5 1 Liberal Conservative Christian $\longrightarrow$ Muslim

Figure 4. The effect of political orientation when the offender was either Christian (black lines) or Muslim (gray lines) on use of words associated with religion (Panel A) and mental health (Panel B) in Experiment 2.

interview with a family member revealed a strained family relationship circling around abuse and suicide." While religion is included in this essay, it is not emphasized or presented as a leading fact. A conservative in the Muslim condition, however, wrote that "detectives found Islam and Muslim searches as well as diagrams in the shooter's apartment... the shooter had recently taken up an increased interest in Muslim and Islam. The matter is still being investigated and it is still yet to be determined if the shooting is linked to terrorism and radical Islam." Again, these samples are not fully representative, but they illustrate how people from different sides of the political spectrum can spread different narratives based on identical information.

\section{Ranked Prioritization of Offender's Experiences}

A mixed analysis testing whether the interaction between offender religion and political ideology depended on offender's religion versus mental health was significant, $F$ $(1,1,066)=10.64, p=.001, \eta_{\mathrm{p}}{ }^{2}=.010$, indicating that the effects of offender religion and political ideology of the participant differed when ranking the importance of religion versus mental health. Again lower numbers indicate a higher ranking and thus greater importance for a given concept. 
Looking first at the importance of religion, main effects of offender religion, $F(1,1,066)=5.42, p=.020, \eta_{\mathrm{p}}{ }^{2}=.005$, and participant political ideology, $F(1,1,066)=5.33, p=$ $.021, \eta_{\mathrm{p}}{ }^{2}=.005$, were both significant, indicating that participants ranked religion as more important when the offender was Christian $(M=2.84, S D=1.19)$ rather than Muslim $(M=$ $3.02, S D=1.18$ ), and that the more conservative and less liberal participants were, the more important they ranked religion to be, $B=-.08, S E=.04, t(1,066)=-2.31, p=.021$. These effects were moderated by an interaction between political ideology and offender religion, $F(1,1,066)=$ $12.62, p<.001, \eta_{\mathrm{p}}{ }^{2}=.012$, with simple slopes analysis revealing that increasing liberal (and decreasing conservative) attitudes predicted significantly lower prioritization of religion when the offender had been described as Muslim, $B=$ $-.21, S E=.05, t(1,066)=-4.06, p<.001$, but did not significantly predict prioritization of religion when the offender had been described as Christian, $B=.04, S E=.05, t(1,066)$ $=.900, p=.369$. Simple effect showed liberals prioritizing religion more for Christian $(M=2.80)$ rather than Muslim $(M=3.22)$ offenders, $t(1,066)=-4.16, p<.001, d=$ -0.25 , whereas conservatives' prioritization of religion did not depend on offender religion $\left(M_{\text {Muslim }}=2.80, M_{\text {Christian }}\right.$ $=2.88), t(1,066)=.870, p=.386, d=0.05$.

There was also a main effect of offender religion on prioritization of mental health, $F(1,1,066)=5.42, p=.020, \eta_{\mathrm{p}}{ }^{2}$ $=.005$, indicating that participants ranked mental health as more important when the offender was Muslim $(M=2.31$, $S D=0.99)$ rather than Christian $(M=2.46, S D=1.07)$. The interaction on mental health was marginally significant, $F(1,1,066)=3.66, p=.056, \eta_{\mathrm{p}}^{2}=.003$, however the simple slopes were nonsignificant. Simple effects suggested that liberals prioritized mental health more for Mus$\lim (M=2.26)$ rather than Christian $(M=2.54)$ offenders, $t(1,066)=3.05, p=.002, d=0.19$, whereas conservatives' prioritization of mental health did not depend on offender religion $\left(M_{\text {Muslim }}=2.35, M_{\text {Christian }}=2.38\right), t(1,066)=.350$, $p=.730, d=0.05$.

\section{Examining the Underlying Process}

We found that political ideology predicted attitudes toward Islam, $B=-.42, S E=.02, t(1,070)=-17.77, p<.001,95 \%$ CI [-.462, -.370], which in turn, moderated by religion of the perpetrator, predicted attribution of the crime to religion, $B=-.44, S E=.08, t(1,070)=-5.64, p<.001$, $95 \%$ CI $[-.599,-.290]$, and the prioritization of reporting about religion, $B=.25, S E=.08, t(1,070)=2.95, p=.003$, $95 \%$ CI [.082, .411]. The indirect path was significant when the perpetrator was Muslim in both outcomes, and when the perpetrator was Christian for the prioritization outcome. There was no mediation for use of religious words.

Once again, we investigated knowledge of Islam and found that knowledge had no significant effect on attitudes even when moderated by political ideology, $F(1,1,066)=$ $2.51, p=.113$. Once again, the mediation analyses included knowledge of Islam as a covariate.

\section{Discussion}

Experiment 2 replicated and extended the effects of Experiment 1 . Once again, we found consistent evidence for motivated reasoning on the basis of political ideology. In contrast to Experiment 1, and as predicted, when we extended the research to a more politically representative sample we found that motivated reasoning biases affect people on both sides of the political aisle. Liberals prioritized religion more when communicating a crime by a Christian rather than Muslim, while also prioritizing mental health more when communicating a crime by a Muslim rather than a Christian. Similarly, conservatives attributed the crime more to religion when it was committed by a Muslim rather than a Christian. Furthermore, analyses of open-ended writings showed that people's political ideology shifted the likelihood of using religion or mental health-related words when communicating the crime to others. Additionally, Experiment 2 further investigated the role of attitudes toward Islam and Muslims as underlying belief systems within political ideology and found support for the results of Experiment 1 such that attitudes toward Islam as a religion but not Muslims as a group explain attributional judgments and determinations of what elements of a story to prioritize in a report. However, and again replicating Experiment 1, attitudes toward Islam were unrelated to a measure of knowledge of Islam, suggesting that negative (or positive) attitudes may come from some source other than a fair familiarity with the religion. Thus, Experiment 2 supports and extends the findings of Experiment 1 to suggest that political ideologies create patterns of motivated reasoning that bias perception and communication of news media.

\section{General Discussion}

How is news processing, creation, and maintenance affected by religious group membership of offenders? Evidence across two large-scale experiments suggests that it critically depends on people's worldview. Specifically, we found that liberals and conservatives both process and communicate crimes in ways that are consistent with their worldviews. Experiment 1 found that in a sample of mostly left-leaning younger adults, liberals prefer using religious attributions for Christians rather than Muslims, while relative conservatives (i.e., in this sample: political centrists) do not show that bias. However, in a more representative sample, we see that both liberals and conservatives interpret 
and communicate news in ways that are consistent with their political worldviews. Furthermore, across both studies we find evidence that attitudes toward Islam, but not toward Muslims, mediate the role of political ideology, which we unpack below.

\section{Motivated Social Cognition and Political Ideology}

Our results support past research indicating the role of motivated social cognition in interpretations of events (Kunda \& Sinclair, 1999). When people have ideological or other aims in their preferred interpretation of the world, these motivations are reflected in how people process information. Importantly, our research extends previous research by showing how easily these motivations can also infect the spread of information at a time when information is being spread faster than ever before. In an extension on recent work (Noor et al., 2019), we also show the bias and discrimination that underlie the motivated cognition of politically relevant events for partisan individuals. Both liberal and conservative participants displayed biased attributions based on the religion of the offenders. In line with arguments that conservatives are motivated to find evidence that Muslims and Islam pose a threat (perhaps due to prejudices or xenophobia associated with conservatism, or participants' perceptions of the need to fight a culture of political correctness; Jost et al., 2003; Lalonde, Doan, \& Patterson, 2000), conservative participants found the religion of the offender to be a more compelling reason for why the crime occurred when the crime was committed by a Muslim rather than Christian. In contrast, in line with arguments that liberals are motivated against finding evidence that Muslims or Islam pose a threat (perhaps due to their valuing of diversity and an accompanying motivation not to see groups they consider positively diverse as posing a threat, or in order to fight perceived biases that they believe other people hold; Carney et al., 2008), liberal participants found the religion of the offender to be a more compelling reason for why the crime occurred when the crime was committed by a Christian rather than Muslim. This finding in particular expands on research showing that cognitive biases are not solely the provenance of the political right (e.g., Ditto et al., 2017; Kahan et al., 2011), supporting a more nuanced and balanced view of biases related to political worldviews.

\section{Prejudice and Principle}

Our analyses of underlying components that are suggested to explain the relationship between political ideology and intergroup judgment found that it was judgments about Islam as a religion rather than Muslims as a group that explained these effects. This would appear to provide some evidence to support the principled conservative perspective (e.g., Sniderman et al., 1989) which argues that many conservative positions reflect principles unfamiliar to many liberals rather than intergroup bias over the argument that conservatism serves as an ideology of intergroup bias (e.g., Jost et al., 2003). However, it is also important to note that in our analyses, knowledge of Islam played no role in determining attitudes toward Islam, which suggests that the attitudes are derived from somewhere other than a fair familiarity with central features of the religion and call into question the principles that might underlie reactions by conservatives that differentiate between Christian and Muslim perpetrators. Additionally, the attitudes toward Islam measure was comparative between religions and differs from a secular critique measure (Imhoff \& Recker, 2012) that may be better suited to access secular attitudes toward Islam.

\section{Muslims and the Media}

Our findings also highlight the important role that political ideology can play in how media reports are created, presented, and then transmitted through organic social networks. Past research suggests that media reports can often display biases against Muslims and other non-Caucasian groups (Scharrer \& Ramasubramanian, 2015), specifically when explaining the cause of a crime (Chen et al., 2015). Furthermore, these biases negatively affect the audience's perceptions of Muslims and other minority social groups (Chen et al., 2015). Thus, it is important to better understand where these biases come from and how they manifest. Our research points to the pervasive quality of politically motivated biases, which can affect information processing and transmission and feed into narratives that support the worldviews of both news reporters and news audiences.

Importantly, this research went beyond measuring attitudes and behavioral intentions to also behaviorally evaluating how people report and communicate politically charged news events. We found that motivated social cognition biases can easily spread beyond people's internalization of news and media reports to the way the news events are then communicated to others. The resulting, already biased communications of such news events can then lead to biased understanding of the news events among the recipients of the communication, even if those do not engage in biased processing themselves, ultimately creating so-called "echo chambers". Finally, this research also highlights that attitudes toward Muslims in particular have increasingly become a distinguishing feature between competing political worldviews and may therefore explain the vitriol in perceived fairness in reporting on issues related to Muslims that is used by political and media commentators as well as media consumers on both sides of the political aisle. 


\section{Limitations and Future Directions}

Despite the consistent results, there were some limitations that should be addressed by future research. First, participants' responses and written reports may have been affected by what audience they thought may be reading their reports. If so, rather than reflecting internalized biases, the biased communication of news events to others could reflect the communicator's concerns that a nonbiased communication could lead to dangerous tendencies among the recipients of the communication. For instance, some liberals might communicate crimes committed by Muslims in a biased way not because they have a biased understanding of the crime, but rather as a strategy aiming to not increase any prejudice among the audience against members of vulnerable groups. Further research may seek to manipulate the imagined audience to determine the extent to which the effects reflect purely internal processes rather than responses or impression management to a perceived audience. Secondly, while we did measure attitudes toward Muslims and Islam, we did not measure attitudes toward Christians and Christianity. Analyzing attitudes toward Christianity may have given us more insight into the motivation behind liberals and conservatives or reduced any bias that may have occurred from asking solely about attitudes toward Muslims. Thus, future research may look more into attitudes toward Christianity and Islam, as well as fundamentalist beliefs that may differentiate between different ways of perceiving the religions. Future research might also include measures of social desirability as well to investigate other potential explanations for why political liberals and conservatives might differ in their attributions of crimes to religion or mental health as a function of the religion of the perpetrator. In addition, because political scales vary across countries, it may also be important to collect similar data in other countries to examine the generalizability of these results. Lastly, measuring political orientation after the experimental manipulation, instead of before, may have biased the results. Thus, future research should improve on the method used here to better capture how people's ideological preferences affect their reporting of news events.

\section{Conclusion}

Although there are many factors that play a role in the different media portrayals of the Muslim offenders in the San Bernardino shooting and the Caucasian offender in the Las Vegas shooting, the two studies reported here suggest that such differences may arise from how reporters and lay people process, generate, and spread information. Importantly, political ideology can bias processing and generation of media reports for people all along the political spectrum.
Increasing awareness of how political ideology can affect how people see and communicate about the world may help them better understand and control the sources and consequences of their biases.

\section{Electronic Supplementary Material}

The electronic supplementary material is available with the online version of the article at https://doi.org/10.1027/ 1864-9335/a000385

ESM 1. Text (.pdf)

Manipulation scenarios, Word library for written report analyses, correlation tables of experimental moderators, and full example written reports and additional analyses for Experiments 1 and 2.

\section{References}

Adelman, L., Yogeeswaran, K., \& Lickel, B. (2019). They're all the same, sometimes: Prejudicial attitudes toward Muslims influence motivated judgments of entitativity and collective responsibility for an individual's actions. Journal of Experimental Social Psychology, 80, 31-38. https://doi.org/10.1016/ j.jesp.2018.10.002

Ames, D. L., \& Fiske, S. T. (2015). Perceived intent motivates people to magnify observed harms. Proceedings of the National Academy of Sciences of the United States of America, 112, 3599-3605. https://doi.org/10.1073/pnas.1501592112

Barberá, P., Jost, J. T., Nagler, J., Tucker, J. A., \& Bonneau, R. (2015). Tweeting from left to right: Is online political communication more than an echo chamber? Psychological Science, 26, 1531-1542. https://doi.org/10.1177/0956797615594620

Brandt, M. J., Reyna, C., Chambers, J.R., Crawford, J.T., \& Wetherell, G. (2014). The ideological-conflict hypothesis: Intolerance among both liberals and conservatives. Current Directions in Psychological Science, 23, 27-34. https://doi.org/ $10.1177 / 0963721413510932$

Carney, D. R., Jost, J. T., Gosling, S. D., \& Potter, J. (2008). The secret lives of liberals and conservatives: Personality profiles, interaction styles, and the things they leave behind. Political Psychology, 29, 807-840. https://doi.org/10.1111/j.14679221.2008.00668.x

Chen, C. Y., Purdie-Vaughns, V., Phelan, J. C., Yu, G., \& Yang, L. H. (2015). Racial and mental illness stereotypes and discrimination: An identity-based analysis of the Virginia Tech and Columbine shootings. Cultural Diversity and Ethnic Minority Psychology, 21, 279-287. https://doi.org/10.1037/a0037881

Crawford, J. T., Kay, S. A., \& Duke, K. E. (2015). Speaking out of both sides of their mouths: Biased political judgments within (and between) individuals. Social Psychological and Personality Science, 6, 422-430. https://doi.org/10.1177/ 1948550614566858

Das, E., Bushman, B. J., Bezemer, M. D., Kerkhof, P., \& Vermeulen, I. E. (2009). How terrorism news reports increase prejudice against outgroups: A terror management account. Journal of Experimental Social Psychology, 45, 453-459. https://doi.org/ 10.1016/j.jesp.2008.12.001

Ditto, P. H., Liu, B., Clark, C. J., Wojcik, S. P., Chen, E. E., Grady, R. H., \& Zinger, J. F. (2017). At least bias is bipartisan: A meta-analytic comparison of partisan bias in liberals and 
conservatives. SSRN Electronic Journal. https://doi.org/ 10.2139/ssrn.2952510

Dovidio, J. F., Kawakami, K., \& Gaertner, S. L. (2002). Implicit and explicit prejudice and interracial interaction. Journal of Personality and Social Psychology, 82, 62. https://doi.org/10.1037/ 0022-3514.82.1.62

Epley, N., \& Gilovich, T. (2016). The mechanics of motivated reasoning. The Journal of Economic Perspectives, 133. https:// doi.org/10.1257/jep.30.3.133

Graham, J., Haidt, J., \& Nosek, B. A. (2009). Liberals and conservatives rely on different sets of moral foundations. Journal of Personality and Social Psychology, 96, 1029. https:// doi.org/10.1037/a0015141

Hayes, A. F. (2013). Introduction to mediation, moderation, and conditional process analysis methodology: A regression-based approach. New York, NY: Guilford Press.

Hodson, G., \& Busseri, M. A. (2012). Bright minds and dark attitudes: Lower cognitive ability predicts greater prejudice through right-wing ideology and low intergroup contact. Psychological Science, 23, 187-195. https://doi.org/10.1177/ 0956797611421206

Hoffman, A. J., \& Wallach, J. (2007). The effects of media bias. Journal of Applied Social Psychology, 37, 616-630. https://doi. org/10.1111/j.1559-1816.2007.00177.x

Hughes, J. S., \& Trafimow, D. (2015). Mind attributions about moral actors: Intentionality is greater given coherent cues. British Journal of Social Psychology, 54, 220-235. https://doi. org/10.1111/bjso.12077

Ifill, G. (2015, December 2). San Bernardino attack suspects killed in police shootout. Public Broadcasting Service.

Imhoff, R., \& Recker, J. (2012). Differentiating Islamophobia: Introducing a new scale to measure Islamoprejudice and secular Islam critique. Political Psychology, 33, 811-824. https://doi.org/10.1111/j.1467-9221.2012.00911.x

Jost, J. T., Glaser, J., Kruglanski, A. W., \& Sulloway, F. J. (2003). Political conservatism as motivated social cognition. Psychological Bulletin, 129, 339-375. https://doi.org/10.1037/00332909.129.3.339

Jussim, L., Crawford, J. T., \& Rubinstein, R. S. (2015). Stereotype (in) accuracy in perceptions of groups and individuals. Current Directions in Psychological Science, 24, 490-497. https://doi. org/10.1177/0963721415605257

Kahan, D. M., Jenkins-Smith, H., \& Braman, D. (2011). Cultural cognition of scientific consensus. Journal of Risk Research, 14 , 147-174. https://doi.org/10.1080/13669877.2010.511246

Kahan, D. M. (2013). Ideology, motivated reasoning, and cognitive reflection. Judgment and Decision Making, 8, 407-424.

Kiley, J. (2017, October). In polarized era, fewer Americans hold a mix of conservative and liberal views. Washington, DC: Pew Research Center. Retrieved from http://www.pewresearch. org/fact-tank/2017/10/23/in-polarized-era-fewer-americanshold-a-mix-of-conservative-and-liberal-views/

Kunda, Z. (1990). The case for motivated reasoning. Psychological Bulletin, 108, 480. https://doi.org/10.1037/0033-2909.108.3.480

Kunda, Z., \& Sinclair, L. (1999). Motivated reasoning with stereotypes: Activation, application, and inhibition. Psychological Inquiry, 10, 12. https://doi.org/10.1207/s15327965pli1001_2

Kunst, J. R., Myhren, L. S., \& Onyeador, I. N. (2018). Simply Insane? Attributing terrorism to mental illness (versus ideology) affects mental representations of race. Criminal Justice and Behavior, 45, 1888-1902. https://doi.org/10.1177/0093854818794742

Lalonde, R. N., Doan, L., \& Patterson, L. A. (2000). Political correctness beliefs, threatened identities, and social attitudes. Group Processes \& Intergroup Relations, 3, 317-336. https:// doi.org/10.1177/1368430200033006
Luguri, J. B., Napier, J. L., \& Dovidio, J. F. (2012). Reconstruing intolerance: Abstract thinking reduces conservatives' prejudice against nonnormative groups. Psychological Science, 23, 756-763. https://doi.org/10.1177/0956797611433877

Mitchell, A., Gottfried, J., Barthel, M., \& Shearer, E. (2016, July 7). Pathway to news. Washington, DC: Pew Research Center. Retrieved from http://www.journalism.org/2016/07/07/pathwaysto-news/

Noor, M., Kteily, N., Siem, B., \& Mazziotta, A. (2019). "Terrorist” or "Mentally IIl": Motivated biases rooted in partisanship shape attributions about violent actors. Social Psychological and Personality Science, 10, 485-493. https://doi.org/10.1177/ 1948550618764808

Persson, A. V., \& Musher-Eizenman, D. R. (2005). College students' attitudes toward blacks and Arabs following a terrorist attack as a function of varying levels of media exposure. Journal of Applied Social Psychology, 35, 1879-1893. https:// doi.org/10.1111/j.1559-1816.2005.tb02200.x

Scharrer, E., \& Ramasubramanian, S. (2015). Intervening in the media's influence on stereotypes of race and ethnicity: The role of media literacy education. Journal of Social Issues, 71, 171-185. https://doi.org/10.1111/josi.12103

Simmons, J. P., Nelson, L. D., \& Simonsohn, U. (2011). Falsepositive psychology: Undisclosed flexibility in data collection and analysis allows presenting anything as significant. Psychological Science, 22, 1359-1366. https://doi.org/10.1177/ 0956797611417632

Sniderman, P. M., Tetlock, P. E., Glaser, J. M., Green, D. P., \& Hout, M. (1989). Principled tolerance and the American mass public. British Journal of Political Science, 19, 25-45. https:// doi.org/10.1017/S0007123400005305

Van Aelst, P., Strömbäck, J., Aalberg, T., Esser, F., de Vreese, C., Matthes, J., ... Stanyer, J. (2017). Political communication in a high-choice media environment: A challenge for democracy? Annals of the International Communication Association, 41, 3-27. https://doi.org/10.1080/23808985.2017.1288551

Weaver, M., \& Lartley, J. (2017, October 3). What we know so far about the Las Vegas shooting. The Guardian. Retrieved from https://www.theguardian.com/us-news/2017/oct/02/lasvegas-shooting-what-we-know-so-far

\section{History}

Received September 23, 2018

Revision received March 3, 2019

Accepted March 6, 2019

Published online July 1, 2019

\section{Authorship}

Samia Habib, Levi Adelman, and Bernhard Leidner developed, conducted, and analyzed the studies, and wrote the manuscript together. Shaheen Pasha and Razvan Sibii helped develop Study 1 and assisted with data collection in Study 1.

\section{ORCID}

Samia Habib

(D) https://orcid.org/0000-0003-2021-1801

\section{Bernhard Leidner}

Department of Psychological and Brain Sciences

Tobin Hall, Room 639

135 Hicks Way

Amherst, MA 01003

USA

bleidner@psych.umass.edu 